\title{
Are cooperative firms more agile? A contingency perspective on small and medium-sized enterprises in agglomerations and peripheral areas
}

\author{
Elisabeth F. Mueller $\mathbb{D}$ - Carola Jungwirth
}

\begin{abstract}
In this study of small and medium-sized enterprises (SMEs) operating in German key technology industries, we investigate whether cooperating with others is an effective strategy for SMEs to enhance their organizational agility. Taking a contingency perspective, we are specifically interested in whether this effect depends on the firm's location in an agglomerated or a peripheral area. Results show that a greater number of cooperative relationships with others is positively associated with SMEs' organizational agility. This effect is stronger for agglomerated than for peripheral firms, suggesting that agglomerated SMEs can seize the abundant opportunities to cooperate in order to counter agglomeration diseconomies such as organizational inertia and mimetic behavior. This finding highlights the importance of absorbing external knowledge gained in cooperative relationships for SMEs' organizational agility. Thereby, the study offers a novel perspective on how agglomerated SMEs can actively prevent being negatively affected by the downsides of agglomerations.
\end{abstract}

Keywords Small and medium-sized enterprises . Organizational agility · Cooperation · Location . Agglomeration · Periphery · Contingency theory

JEL classifications $\mathrm{C} 12 \cdot \mathrm{C} 83 \cdot \mathrm{D} 83 \cdot \mathrm{L} 26 \cdot \mathrm{R} 12$

E. F. Mueller $(\bowtie) \cdot$ C. Jungwirth

School of Business, Economics and Information Systems, University of Passau, Innstrasse 71, 94036 Passau, Germany

e-mail: elisabeth.mueller@uni-passau.de

\section{Introduction}

In today's heterogeneous, volatile business environments, firms face various challenges such as rapid technological changes, demand uncertainty, and product obsolescence. Organizational agility is seen as a key ability for firms to successfully deal with these challenges (Doz and Kosonen 2008; Tallon and Pinsonneault 2011). Organizational agility refers to a company's ability to proactively drive its external environment and react flexibly to ever-changing customer demands, competitive moves, or continuous improvements along the value chain (Tallon and Pinsonneault 2011; Lim et al. 2017). In this regard, agile organizations manage both supply-side uncertainty and demand shocks, and adjust strategy and technology as necessary and desirable.

While research has mainly focused on exploring the beneficial effects of organizational agility on firm performance, insights into the antecedents of agility are more limited despite their importance for creating the conditions necessary to survive in today's competitive environment (e.g., Nemkova 2017). For example, Yusuf et al. (2014) are the first to highlight the role of partnering opportunities as a driver for organizational agility in a business environment that is characterized by

C. Jungwirth

e-mail: carola.jungwirth@uni-passau.de 
dynamic change and uncertainty. Cooperation between firms has the potential to increase the involved firms' organizational agility since cooperative relationships deliver novel information and knowledge, which are required for actions such as changes in strategy and technology (Rothwell and Dodgson 1991; Chun and Mun 2012). Specifically, firms may take advantage of cooperative relationships in the actual locational environment, just as they use other site-specific characteristics embedded in their surroundings to shape effective organizing strategies and routines (Galbraith et al. 2008). However, while Yusuf et al. (2014) show some evidence that firms' agility is higher in agglomerated cluster regions with abundant partnering opportunities, the actual impact of the environmental context, i.e., an agglomerated as opposed to a peripheral location, as a source of conditionality remains unclear. This knowledge gap is surprising given that prior research suggests that location-specific characteristics may affect firms' strategic heterogeneity and, ultimately, competitive advantage (Furman 2003).

In this study, we therefore adopt a contingency perspective and question whether the relationship between cooperative relationships and organizational agility is contingent on the locational environment of the firm. To analyze this research question, we use a unique data set of 440 small and medium-sized enterprises (SMEs) operating in key technology industries in the German state of Bavaria. SMEs are appropriate units of analysis because they have limited abilities in shaping their surroundings and therefore depend more critically on the ability to identify and respond to the threats and opportunities presented by the external environment (Smallbone et al. 1999; Payne et al. 2009).

This study makes the following contributions to the literature. First, our study contributes to the literature on organizational agility in SMEs by highlighting interfirm cooperation as an important driver of this ability. We draw on the main arguments of the resource-based view (e.g., Barney 1991; Lavie 2006) to argue that cooperative relationships provide SMEs with the resources that are necessary to enhance their agility. We then adopt a contingency perspective and posit alternative hypotheses concerning the role of SMEs' location in this relationship. We argue on the one hand that agglomerated firms may profit more than peripheral firms from cooperative relationships owing to lower transaction costs of cooperation or ample cooperation opportunities that provide complementary resources. On the other hand, we argue that peripheral firms may benefit more than agglomerated firms from cooperative relationships, because they have a stronger inherent focus on cooperation since they depend on additional knowledge and resource flows to compensate for locational disadvantages and to prevent isolation. With this approach, we not only extend the limited body of research on the drivers of organizational agility, but also clarify some of the conditionality of the findings of prior literature (e.g., Yusuf et al. 2014).

Second, we add to the conversation about the role of location by highlighting that firm location influences the investigated relationship between a cooperation-based strategy and organizational agility. Interestingly, there is increasing evidence of significant differences in spatial tendencies among firms, even within the same industrial sector (e.g., Galbraith et al. 2008), which further confirms the need to explore the contingency effects of different locations. This study contributes to shifting the perspective of this conversation from an outcomeoriented discussion to a contingency-oriented discussion. So far, traditional location models have focused on weighing agglomeration benefits (such as lower transportation and transaction costs, abundant supply of specialized inputs, superior innovation outcomes) and agglomeration costs (such as negative selection effects, homogenous macrocultures, organizational inertia) to explain location decisions, firm strategy, and related performance outcomes (e.g., Shaver and Flyer 2000; Pe'er and Keil 2013). More recent contributions, however, have begun exploring under which conditions spatial co-location is advantageous and how a firm's ability to act responsively and flexibly to their locational environment, be it an agglomerated region or not, results in superior performance (e.g., Berchicci et al. 2011; Yusuf et al. 2014; Lim et al. 2017). For example, Lim et al. (2017) show that under certain conditions such as high demand uncertainty, conventional location models can be inadequate for designing optimal supply chains. We tie in with this conversation and investigate the role of location for SMEs' endeavors to achieve agility, which is a relevant ability for SMEs to develop and grow in uncertain and volatile business environments.

Finally, using a unique data set of 440 SMEs, we provide empirical evidence on a specific type of firm that is understudied in the literature owing to data availability constraints, but whose contribution to economic welfare is important in many countries (e.g., Acs 1999; Leitner and Güldenberg 2010). Developing 
organizational agility is likely to be a challenge for SMEs. Even though they are typically leaner and more flexible compared with large organizations, resource constraints and a lack of slack resources hinder SMEs in detecting external opportunities or in responding to environmental changes (Arbussa et al. 2017, Chan et al. 2019). These challenges, however, may be mitigated by a cooperation-based strategy that leverages cooperative relationships to gain access to necessary resources and capabilities (Chan et al. 2019). We demonstrate in this study that cooperative relationships indeed are positively related to SMEs' organizational agility. Results show this effect to be stronger for agglomerated than for peripheral SMEs for high numbers of cooperative relationships, suggesting that within agglomerations SMEs can counter agglomeration diseconomies by seizing various opportunities to cooperate. These findings support the rationale that agglomerations are vibrant environments that offer SMEs various opportunities to react flexibly to future challenges. More importantly, the results suggest that the power to counter agglomeration diseconomies is actually inherent in agglomerations. SMEs can make use of this power by establishing cooperative relationships, ultimately increasing their agility.

\section{Theoretical background and hypotheses development}

2.1 Cooperative relationships and organizational agility

In today's competitive, heterogeneous business landscapes and volatile business environments, firms need to be alert and able to change continuously but also link recent trends to the past and future strategic actions. These environmental conditions emphasize the ability of firms to provide proactive actions and adaptive responses - an ability that is known as organizational agility. Organizational agility is defined as "the ability to detect and respond to opportunities and threats with ease, speed, and dexterity" (Tallon and Pinsonneault 2011, p. 464). Agile companies are more likely to maintain their competitiveness and to successfully cope with environmental challenges such as rapid technological changes, demand uncertainty, and product obsolescence (Gligor et al. 2013; Lim et al. 2017).

To be flexible and responsive to changes, firms coordinate activities across different business units, across functions, or even across firms (Sharifi and Zhang 1999; Lim et al. 2017). For example, the ability to rapidly coordinate activities - to be agile - across the supply chain is a prerequisite for the collective success of the supply chain partners (Gligor et al. 2013). Organizational agility is gaining even greater importance to the competitiveness of firms in information-intensive environments, where information technology competencies and alignment contribute to enabling and facilitating firms' agility (Leitner and Güldenberg 2010; Tallon and Pinsonneault 2011; Chakravarty et al. 2013). However, since merely spending more on IT does not lead to greater agility whereas spending in a way to enhance IT capabilities does (Lu and Ramamurthy 2011), research on agility increasingly spotlights the strategic decisionmaking of top managers. Within this context, decisionmaking for top managers in fields that are associated with agility is complicated by the seeming contradiction of making farsighted choices and keeping commitments on the one hand and staying flexible and ready to reassess the path taken on the other hand (Doz and Kosonen 2008; Nemkova 2017).

SMEs face particularly strong challenges in demonstrating strong organizational agility. They consider it demanding to detect and respond to ever-changing environments since they lack abundant resources to develop new knowledge, which would be required for any adaptation (Rothwell and Dodgson 1991; Naudé et al. 2014; Nemkova 2017). Moreover, SMEs often operate in niche markets and risk the collapse of their business model if they fail to react to environmental changes that call for a major strategy revision or a product portfolio adaptation (Chan et al. 2019). Being able to establish adequate partnerships, to dynamically adapt ones' capabilities, and to develop agile supply chains seem to be effective strategies to meet these challenges (RodríguezSerrano and Martín-Armario 2017; Partanen et al. 2018). SMEs even use such partnerships as strategic instruments to overcome their resource constraints (Findikoglu and Watson-Manheim 2015).

In line with the resource-based view (e.g., Penrose 1959; Rumelt 1984; Barney 1991; Lavie 2006), firms benefit from connecting with others through cooperative agreements in a variety of ways. First, they gain access to complementary resources their partners possess, which they themselves are not able to acquire because of resource immobility or are not able to develop internally owing to prohibitively high costs (Das and Teng 2000; Colombo et al. 2006). In this context, 
complementary resources are essential if firms are to capture the full benefits associated with a strategy, a technology, or an innovation. In addition to gaining access to complementary resources, firms achieve synergies via the sharing of knowledge (Gulati 1998; Tsang 2000), and they learn from the skills and capabilities of their partners (Cohen and Levinthal 1990; Gulati 1998). In a volatile and uncertain economic environment where technological trends evolve rapidly, companies collaborate to extend their resource and knowledge base, enabling them to better adapt to these environments in an agile way and therefore to obtain or maintain a sustainable competitive advantage (e.g., Powell et al. 1996).

Earlier research has endorsed these resource-driven motivations for SMEs' cooperative behavior and has suggested that SMEs benefit from cooperation in terms of profit growth (Partanen et al. 2018), international performance (Ripollés and Blesa 2019), and innovation (Gnyawali and Park 2009). Since they often lack formal internal R\&D activities, SMEs depend even more on access to external knowledge to accumulate technological or managerial knowledge and to be successful at innovation than large, diversified, multi-establishment firms (Rothwell and Dodgson 1991; Acs et al. 1994; Smallbone et al. 1999; Payne et al. 2009; Chun and Mun 2012; Radicic et al. 2018). Given the SMEs' resource constraints, they perceive themselves to be more "vulnerable" than larger firms, which increases the likelihood to partner with others to be able to compete with stronger players (Gnyawali and Park 2009). To acquire relevant complementary resources, SMEs build alliances or make acquisitions, but the actual value of the alliance or acquisition depends on the ability of the company to discover and conduct resource combinations (Wiklund and Shepherd 2009). Cooperation through alliances, for example, can enable SMEs to survive under high environmental uncertainty and rapid technological obsolescence because external knowledge flows enhance internal learning and keep SMEs flexible (Hoffmann and Schlosser 2001). These knowledge flows and further external relationships enable SMEs to align and adapt internal processes (Bi et al. 2018). For these reasons, cooperative relationships can be considered as a driver for organizational agility in a business environment that is characterized by dynamic change and uncertainty.

An intuitive measure of these cooperative relationships is their absolute number (Newbert and Tornikoski
2012). Each additional relationship increases the flow of information and ideas to the focal SME and facilitates access to resources needed for agile behavior. Therefore, establishing numerous cooperative relationships may offer an effective means for SMEs to enhance their organizational agility. Hence, we state the following hypothesis:

Hypothesis 1: A higher number of cooperative relationships is positively related to a SME's organizational agility.

\subsection{SME location as a contingency factor}

Research regarding the influence of location choice on the behavior of firms provides ambiguous results with respect to successful strategies in agglomerated and peripheral areas. While agglomeration economies offer benefits to agglomerated firms, agglomeration diseconomies have the potential diminish these advantages, which could motivate firms to locate in peripheral areas where they run a lower risk of unintentional external knowledge spillovers (e.g., Baptista and Swann 1998; Kalnins and Chung 2004; Alcácer and Chung 2007). To contribute to the ongoing discussion of the role of agglomerations versus that of peripheral locations, we follow a contingency theory approach. Contingency theory is guided by the assumptions that there is no universally optimal strategy and that any strategy is not equally effective under different environmental conditions (Galbraith 1973; Schoonhoven 1981). Contingency theory has a long and ongoing tradition in entrepreneurship research. For example, it has been shown that the external environment is a meaningful factor in explaining the effects of strategic posture and competitive tactics on the performance of small firms (Covin and Slevin 1989) or of network growth on organizational emergence (Newbert and Tornikoski 2012). The contingency perspective allows us to consider the influence of the environmental context on a specific strategyperformance relationship, which, in our case, is the relationship between a cooperation-based strategy and organizational agility as the outcome of interest.

By following this approach, we investigate the strength of the relationship between cooperation and agility for SMEs located in peripheral areas (so-called geographic blind spots) as opposed to SMEs located in agglomerations (so-called geographic hot spots) (Pouder and St. John 1996). Geographic hot spots and blind spots differ in their "locational quality." 
Locational quality refers to the aggregated prevalence of location-bounded characteristics, such as the local resource endowment, the degree of local competition, and the degree of local cooperation, which are at least in the short run beyond the direct control of managers (Furman 2003; Payne et al. 2009).

Geographic hot spots are characterized by a strong agglomeration of economic activity (Pouder and St. John 1996). They represent places of agglomerated firms and institutions, such as industrial districts, innovative milieus, and regional clusters, as well as metropolitan areas and major cities featuring above-average locational quality (Dicken and Lloyd 1990; Porter 2000). SMEs located in close proximity benefit from the spatial concentration of similar activities within a region as a result of their access to specialized labor, specialized inputs, and knowledge spillovers (Almeida and Kogut, 1997; McCann and Folta 2008; Rivera et al. 2016). The economic vibrancy of a hot spot is not attributed to the mere location decisions of firms, which are rather seen as the sine qua non, but is rather due to the local dynamism created by external economies of scale available to each firm from its spatial conjunction with other firms. These external economies of scale thus enable SMEs geographically co-located with others to compete successfully with large, vertically integrated corporations that benefit from internal economies of scale. Co-location in agglomerations, where local resources and partnering opportunities are abundant, increases the potential for organizational agility, growth, and development for several reasons. First, SMEs can choose from a large variety of potential cooperation partners and access complementary resources (Barney 1991; Lavie 2006; Rivera et al. 2016). Second, the transaction costs of cooperation are low in agglomerations (Porter 2000). Third, the competitive characteristics in agglomerations (intense competition, increased transparency, high absorptive capacity) create a strong need for cooperation along with substantial benefits from cooperation (Gordon and McCann 2000; Maskell 2001; Pe'er and Keil 2013).

While the first two mechanisms build on well-known arguments established by the resource-based view and transaction cost economics, the third draws on three specific competitive characteristics inherent to agglomerations. First, intense competition among co-located firms within agglomerations may compel firms to closely cooperate with others if they are not confident they can withstand competitive forces on their own or respond to market and technology changes on the basis of their present resource endowments (Gordon and McCann 2000). Also, varying demand characteristics or rapid market and technology changes pressure firms to disaggregate production activities across several firms in the agglomeration, with each firm specializing in a specific set of activities which - if properly recombined across firms through cooperation-enhances their overall flexibility in reacting to heterogeneous customer demand (Schilling and Steensma 2001; Arikan and Schilling 2011).

Second, spatial co-location and frequent interactions within the agglomeration increase the transparency of each firm's strategic moves, resource endowments, production costs, or technologies (Maskell 2001; Bathelt et al. 2004). Opportunistic behavior will immediately be noticed and sanctioned (Maskell 2001). Therefore, firms that seek to exploit others' resources without contributing to a cooperative relationship are deterred from locating in an agglomeration (Kalnins and Chung 2004). Owing to these mechanisms, the incumbent firms feel reassured of the remaining firms' benevolent intentions to cooperate, thus increasing the likelihood that they will enter into cooperative partnerships that enable them to cope with the complex business environment. Third, the above-discussed mechanisms lead to an agglomeration of companies that possess above-average resource endowments, knowledge stocks, and innovation capacity. Thus, the companies have the level of absorptive capacity necessary for benefiting from co-location (Cohen and Levinthal 1990). More precisely, higher knowledge stocks and greater absorptive capacity enable firms to profit from external knowledge spillovers (Giuliani and Bell 2005; McCann and Folta 2011), which can be stimulated through cooperation.

Since these mechanisms are effective only in the case of SMEs' sufficient geographic proximity, they are unique to agglomerations and are absent from peripheral areas. Therefore, we state the following hypothesis:

Hypothesis 2a: The positive relationship between a higher number of cooperative relationships and organizational agility is stronger for SMEs located in agglomerated areas.

Geographic blind spots are characterized by a relatively sparse population of firms and institutions, underspecialized local (input) markets, and belowaverage locational quality, as found in peripheral regions such as smaller cities, villages, and hamlets (Dicken and Lloyd 1990; Virkkala 2007; Gherhes 
et al. 2018). A vast number of companies are located in these blind spots outside major agglomerations of geographic activity (Lublinski 2003; McCann and Folta 2008). Firms may deliberately choose to locate in peripheral areas rather than agglomerations if they estimate that agglomeration diseconomies outweigh agglomeration economies. For example, companies will avoid agglomerations in which they expect the incumbents to exploit knowledge spillovers without contributing to them (Shaver and Flyer 2000; Kalnins and Chung 2004). If firms possess superior technological knowledge, they take into account the costs of outward knowledge spillovers and do not locate in areas with high industrial innovative activity (Alcácer and Chung 2007). Also, firms avoid locating in agglomerations owing to congestion effects, becoming preeminent in the convergence phase of an agglomeration in the form of diseconomies of scale, lower profit margins owing to increased local competition, an increased salary level and limited supply of the workforce, or excessive specialization (Pouder and St. John 1996; McCann and Folta 2008; Amorós et al. 2013). Additionally, managers of agglomerated firms develop homogeneous mental models biased by the hot-spot environment, resulting in firms' mimetic competitive practices and rigid organizational structures (Pouder and St. John 1996).

While SMEs located in geographic blind spots escape agglomeration disadvantages, they nevertheless have to cope with below-average locational quality in peripheral areas. They face less abundant local resources in terms of specialized human capital, input factors, or business services, fewer opportunities to cooperate with neighboring firms, and lower local competition (Virkkala 2007; Coombs et al. 2009; Payne et al. 2009). While the former two conditions are locational disadvantages, lower local competition can be either advantageous if the firm establishes and maintains a local monopoly or disadvantageous if the lack of competition paralyzes innovation dynamics and impedes technological progress.

Conventional wisdom would suggest that these firms are at a competitive disadvantage relative to their agglomerated competitors, but convincing evidence for lower performance is lacking (Baptista and Swann 1998; Patterson and Anderson 2003; Kukalis 2010). Thus, we argue that SMEs located outside of major agglomerations may have strategic options for mitigating locational competitive disadvantages (Coombs et al.
2009). By locating in a peripheral area, for example, SMEs are more independent from other producers in making strategic decisions and are able to avoid lock-in effects such as increasing rigidity and mimetic behavior, providing the basis for being flexible and responsive to environmental changes (Suarez-Villa and Walrod 1997). Correspondingly, managers of peripheral SMEs perceive market dynamism to be higher in the periphery than in the agglomeration (Amorós et al. 2013). However, unfavorable location-bounded factors, such as a paucity of resources, enforce SMEs' need to cooperate and to seek partners on a local, regional, or international level because they themselves are unlikely to obtain the necessary resources to pursue various strategic activities from the environment (Payne et al. 2009). For example, SMEs located in blind spots more strongly engage in networking activities to overcome resource constraints when entering foreign markets (Westhead et al. 2004). By gaining access to partners' resources or knowledge, they are thus able to compensate potential locational disadvantages resulting from isolation, resource scarcity, and low locational quality and to react flexibly to the ever-changing business environment offering foreign market opportunities. Therefore, SMEs located in blind spots are expected to rely on cooperative relationships which support them in becoming agile and flexible and consequently in obtaining or maintaining a sustained competitive advantage. Hence, we hypothesize:

Hypothesis $2 \mathrm{~b}$ : The positive relationship between a higher number of cooperative relationships and organizational agility is stronger for SMEs located in peripheral areas.

\section{Research design}

\subsection{Sample and procedure}

Our goal was to gather comprehensive survey data on the strategic postures, location, and agility of SMEs in the German state of Bavaria. We chose this sampling context for a number of reasons. First, we targeted SMEs as the relevant units of analysis because smaller firms are considered to have more limited abilities in shaping their external environment than larger firms (Smallbone et al. 1999; Payne et al. 2009). Therefore, their success depends "especially on their ability to identify and respond to the threats and opportunities presented by their external environment; in other words, 
to adapt or adjust to external environmental conditions, which can be identified at different geographical scales (i.e. global, national, regional and local" (Smallbone et al. 1999, p. 109). Second, empirical studies on SMEs regularly collect primary data using a sample survey research design since SMEs are neither obligated to disclose financial information nor are they willing to provide reliable strategic information in the form of industry reports and the like. As survey participants needed to be able to generalize about the strategic postures as well as the local environment in which the firm is embedded, we followed a key informant approach (Kumar et al. 1993). We targeted owner-managers, CEOs, and executives as key informants as they are expected to have complete and specialized knowledge about the variables of interest. One key informant per firm was invited to participate in the survey. Third, we focused on companies located within a limited geographic region (the German state of Bavaria) as empirical tests of differences between firms that are located physically too far from each other are difficult since macro- or mesoeconomic factors may vary across physical distance (Furman 2003; Lublinski 2003). Hence, while located in different geographic settings, the surveyed hot spot and blind spot firms had to be located physically as close to each other as possible.

We were granted unique access to the company database "Key Technologies in Bavaria," administered by the Bavarian Ministry of Economic Affairs and Media, Energy and Technology, which contained potential key informant contacts for our study. This database is the most comprehensive database offering contact information about Bavarian SMEs operating in the 22 most important key technology sectors in Bavaria. We thoroughly validated the contact and firm data from this source to avoid potential errors with regard to duplicate entries, firm names, and e-mail addresses. We invited a population of 12,399 key informants of Bavarian SMEs to participate in our web-based survey, which was also available in a printable version of the questionnaire so that respondents could opt to fill in a paper sheet instead of using the web interface.

After nine weeks and three reminder emails, 738 key informants had participated in the survey, resulting in a response rate of $5.95 \%$. However, the sample required adjustment owing to drop-outs (unit non-response) and missing values (item non-response). After these corrective steps, the resulting sample of valid responses from the survey contained 440 entries. In the final data set,
230 firms were located in geographic hot spots and 210 firms were located in geographic blind spots. Of the total number of 440 firms, $38 \%$ had fewer than 10 employees (micro enterprises), $43 \%$ had between 10 and 49 employees (small enterprises), and 19\% had between 50 and 249 employees (medium-sized enterprises). The industries most strongly represented were the mechanical engineering industry $(13.0 \%)$, the ICT industry $(13.0 \%)$, the construction industry $(11.8 \%)$, and the electrical engineering and electronic industry (10.5\%). Respondents ranged in age from 26 to 93 years $($ mean $=50)$ and had on average 23 years of relevant industry experience. More than four-fifths were male and more than three-fifths held a university degree. Almost $80 \%$ of the respondents were the founders or the CEOs of the surveyed firms.

Table 1 gives an overview of the sample characteristics.

\subsection{Variables}

For all analyses, the dependent variable was the firm's organizational agility (see the Appendix for information on the exact items of the variables and their reliability and validity). We measured this variable with five items from the organizational agility scale (Tallon and Pinsonneault 2011). The scale captures organizational agility by asking, "How easily and quickly can your firm perform the following actions?" Survey participants evaluated five items on an ordinal Likert-type scale anchored at 1 (strongly disagree) and 5 (strongly agree): (1)...respond to changes in aggregate consumer demand, (2) ...customize a product or service to suit an individual customer, (3) ... react to new product or service launched by competitors, (4) ...expand into new regional or international markets, (5) ...change (i.e., expand or reduce) the variety of products/services available for sale.

Our first independent variable, cooperative relationships, represents a firm's total number of cooperative relationships. The variable encompasses both vertical cooperative relationships with suppliers or customers and horizontal cooperative relationships with competitors (Radicic et al. 2018). It also includes cooperation in different activities such as R\&D, marketing, and manufacturing (Gulati 1998). Our second independent variable, blind spot, is a dummy variable that captures the characteristics of the firms' location (Pfeffer 2017). Following the procedure of Stearns et al. (1995), on the 
Table 1 Sample characteristics

\begin{tabular}{|c|c|c|c|c|c|}
\hline & Frequency & Percent & & Frequency & Percent \\
\hline \multicolumn{3}{|l|}{ Location } & \multicolumn{3}{|l|}{ Size } \\
\hline Blind spot & 210 & 47.7 & Less than 10 employees & 167 & 38.0 \\
\hline \multirow[t]{2}{*}{ Hot spot } & 230 & 52.3 & 10-49 employees & 189 & 43.0 \\
\hline & & & 50-249 employees & 84 & 19.1 \\
\hline \multicolumn{6}{|l|}{ Industry } \\
\hline Mechanical engineering & 57 & 13.0 & Chemical & 13 & 3.0 \\
\hline $\mathrm{CT}$ & 57 & 13.0 & Commerce & 13 & 3.0 \\
\hline Construction & 52 & 11.8 & Media & 11 & 2.5 \\
\hline Electrical engineering and electronics & 46 & 10.5 & Advanced materials & 9 & 2.0 \\
\hline Business \& professional services & 33 & 7.5 & Environmental technology & 9 & 2.0 \\
\hline Food & 22 & 5.0 & Mechatronics & 7 & 1.6 \\
\hline Medical engineering & 19 & 4.3 & Biotechnology & 5 & 1.1 \\
\hline Automotive & 15 & 3.4 & Power engineering & 4 & 0.9 \\
\hline Logistics & 15 & 3.4 & Aerospace & 3 & 0.7 \\
\hline Forestry and timber & 14 & 3.2 & Others & 36 & 8.2 \\
\hline \multicolumn{6}{|l|}{ Respondent characteristics } \\
\hline & Frequency & Percent & & Frequency & Percent \\
\hline \multicolumn{3}{|l|}{ Gender } & \multicolumn{3}{|l|}{ Position } \\
\hline Male & 361 & 82.0 & Founder & 138 & 31.4 \\
\hline Female & 77 & 17.5 & CEO & 206 & 46.8 \\
\hline Missing & 2 & 0.5 & Senior manager & 75 & 17.0 \\
\hline \multicolumn{3}{|l|}{ University degree } & Other executive position & 19 & 4.3 \\
\hline Yes & 267 & 60.7 & Missing & 2 & 0.5 \\
\hline No & 167 & 38.0 & & & \\
\hline \multirow[t]{2}{*}{ Missing } & 6 & 1.4 & & & \\
\hline & & Mean & SD & Min & Max \\
\hline \multicolumn{2}{|l|}{ Age (in years) } & 50.2 & 10.8 & 26 & 93 \\
\hline \multicolumn{2}{|l|}{ Industry experience (in years) } & 23.1 & 11.5 & 1 & 60 \\
\hline \multicolumn{2}{|c|}{ Experience with international business (in years) } & 15.7 & 11.3 & 0 & 55 \\
\hline
\end{tabular}

basis of their zip code, surveyed firms were objectively assigned a value of " 0 " if located in a geographic hot spot ("Core City" or "Inner Conurbation Area") and a value of "1" if located in a geographic blind spot ("Outer Conurbation Area" or "Rural Area"). Whether a specific zip code was related to a geographic hot spot or blind spot was based on data provided by the German Federal Institute for Research on Building, Urban Affairs, and Spatial Development. On the basis of urban-rural relationships using 23 indicators such as the unemployment rate, GDP per capita, demographic development, commuting distances, population density, and social and technical infrastructure, the 96 Bavarian administrative territorial entities and their related zip codes have been divided into 33 geographic hot spots and 63 geographic blind spots.

To account for alternative factors that could influence a firm's organizational agility, we included a number of ordinal control variables. Each of these variables was measured by multiple items on an ordinal Likert-type scale anchored at 1 (strongly disagree) and 5 (strongly agree). First, we controlled for several factors that describe a firm's external environment. The variable environmental complexity was captured by five items that 
were adapted from O'Donnell (2000) and describe the extent to which co-located firms are interdependent. We adapted two items from Jansen et al.'s (2006) environmental competitiveness scale to measure the extent to which a firm's local business environment is characterized by intense competition. Moreover, we developed one item based on Jansen et al. (2006) that taps into the rate of change of the local business environment and captures the variable environmental dynamism. We also controlled for factors that describe the strategic posture of the firm. We included measures for the entrepreneurial orientation (Miller 1983; Wiklund et al. 2009) of a firm that is demonstrated by the extent to which top managers are inclined to favor change and innovation, to compete aggressively with other firms, and to take business-related risks. We used Miller's (1983) widely used eight-item scale for entrepreneurial orientation which captures the three dimensions innovativeness, proactiveness, and risk-taking. In addition, we controlled for the firms' generic business strategy. Four items borrowed from Patterson and Anderson (2003) were combined to capture a firm's orientation towards a differentiation business strategy during the past five years.

We also controlled for firm age, sales, and the number of employees. We asked the respondents to provide information on these variables in ordinal categories in order to avoid high drop-out rates when asking for disclosure of such sensitive data. The ordinal categories of the variable employees and sales followed the definition of micro, small, and mediumsized enterprises by the European Commission (2015). The ordinal categories of age encompassed three categories for young firms (less than eight years) and three categories for established firms (eight years and more) (LiPuma et al. 2013). ${ }^{1}$ We then generated dummy variables based on the ordinal categories that were included in the regression analysis. Finally, we controlled for the main line of business activity (dummy variable service: 1 = service; $0=$ manufacturing). We did not use finer industry breakdowns in the analysis because we found no significant differences, and we sought to conserve degrees of freedom in the regression equations.

\footnotetext{
${ }^{1}$ Ordinal categories of these variables: employees: $1:<10$ employees, 2: 10-49 employees, 3: 50-249 employees; sales: 1: $\leq 2$ mEUR, 2: $3-$ 10 mEUR, 3: 11-50 mEUR; age: 1: < 1 year, 2: 1-3 years, 3: 4 7 years, $4: 8-25$ years, $5: 26-50$ years, $6:>50$ years.
}

\section{Analysis and results}

\subsection{Descriptive analysis}

Means, standard deviations, minimum and maximum values for the study variables are shown in Table 2 . The dependent variable organizational agility and all of the control variables measured by Likert-type items (e.g., innovativeness) are ordinal variables. We combined the items associated with each variable by calculating their mean, and interpret the resulting values as ordered categories. For example, calculating the mean of the five items measuring organizational agility results in an ordinal variable that consists of 20 ordered categories ranging from 1 to 5 .

Table 3 shows the correlation statistics. The correlation analysis suggests that organizational agility is positively and significantly associated with the number of cooperative relationships. This result indicates some bivariate support for our theoretical reasoning in Hypothesis 1. Organizational agility is also positively and significantly correlated with environmental dynamism, which emphasizes the importance of agility in dynamic environments. With regard to the strategic posture of a firm, organizational agility is positively and significantly associated with the entrepreneurial orientation of the firm reflected by innovativeness, proactiveness, risktaking, and with a differentiation business strategy. In terms of firm age, relatively established firms (825 years) are positively and significantly associated with organizational agility, while older firms (>50 years) show a negative and significant association. Further, micro enterprises having less than 10 employees and an annual turnover of EUR 2 million or less are positively and significantly associated with organizational agility. In addition, the results suggest that the number of cooperative relationships is positively and significantly correlated with environmental complexity, indicating a strong need to partner with others in complex environments, but negatively and significantly associated with micro enterprises.

Correlation statistics also show some significant results among the control variables. Specifically, the variables innovativeness, proactiveness, and risk-taking, which all describe the entrepreneurial orientation of a firm, are significantly correlated with each other. The variables environmental dynamism, environmental complexity, and environmental competitiveness, which all describe a firm's external environment, are also 
Table 2 Descriptive statistics of study variables

\begin{tabular}{|c|c|c|c|c|}
\hline Variables & Mean & SD & Min & $\operatorname{Max}$ \\
\hline 1. Organizational agility & 3.62 & 0.75 & 1 & 5 \\
\hline 2. Cooperative relationships & 23.51 & 47.85 & 0 & 310 \\
\hline 3. Blind spot & 0.48 & 0.50 & 0 & 1 \\
\hline 4. Environmental dynamism & 2.88 & 1.23 & 1 & 5 \\
\hline 5. Environmental complexity & 2.70 & 1.03 & 1 & 5 \\
\hline 6. Environmental competitiveness & 2.50 & 0.94 & 1 & 5 \\
\hline 7. Innovativeness & 3.16 & 0.95 & 1 & 5 \\
\hline 8. Proactiveness & 3.64 & 1.02 & 1 & 5 \\
\hline 9. Risk-taking & 2.76 & 1.01 & 1 & 5 \\
\hline 10. Differentiation & 4.14 & 0.62 & 2 & 5 \\
\hline 11. Employees $<10$ & 0.38 & 0.49 & 0 & 1 \\
\hline 12. Employees 10-49 & 0.43 & 0.50 & 0 & 1 \\
\hline 13. Employees 50-249 & 0.19 & 0.39 & 0 & 1 \\
\hline 14. Age $<1$ year & 0.01 & 0.10 & 0 & 1 \\
\hline 15. Age $1-3$ years & 0.03 & 0.17 & 0 & 1 \\
\hline 16. Age 4-7 years & 0.07 & 0.26 & 0 & 1 \\
\hline 17. Age 8-25 years & 0.37 & 0.48 & 0 & 1 \\
\hline 18. Age $26-50$ years & 0.28 & 0.45 & 0 & 1 \\
\hline 19. Age $>50$ years & 0.24 & 0.43 & 0 & 1 \\
\hline 20. Sales $\leq 2 \mathrm{~m}$ & 0.56 & 0.50 & 0 & 1 \\
\hline 21. Sales $3-10 \mathrm{~m}$ & 0.33 & 0.47 & 0 & 1 \\
\hline 22. Sales $11-50 \mathrm{~m}$ & 0.11 & 0.31 & 0 & 1 \\
\hline 23. Service & 0.42 & 0.49 & 0 & 1 \\
\hline
\end{tabular}

The dummy variables capturing the number of employees, age, and sales were generated based on the categories of the original ordinal variables: employees: $1:<10$ employees, 2: 10-49 employees, 3: 50-249 employees; age : $1:<1$ year, 2: 1-3 years, 3:47 years, $4: 8-25$ years, $5: 26-50$ years, $6:>50$ years; sales: $1: \leq 2$ mEUR, 2: 3-10 mEUR, 3: 11-50 mEUR

significantly associated with one another. These results are in line with our expectations as they emphasize the idea that the variables are conceptually linked to one another.

Moreover, the dummy variables controlling for the number of employees, age, and sales show a strong and significant association with one another. As this could lead to unreliable and unstable estimates of regression coefficients, we control for this potential multicollinearity problem in the robustness tests.

\subsection{Validity and reliability of study variables}

We assessed the validity and reliability of all items pertaining to our multi-item variables through an exploratory factor analysis. The table in the Appendix summarizes the results. Exploratory factor analysis clearly replicated the intended factor structure. Factor loadings were above 0.61 , except for one item belonging to the differentiation business strategy variable and one item belonging to the organizational agility variable that had factor loadings of 0.43 and 0.56 , respectively, but were retained in the model given their theoretical importance. Cronbach's alpha for the variables ranged from 0.59 to 0.87 and values for composite reliability ranged between 0.76 and 0.89 , showing that overall, the variables exhibit satisfactory internal reliability.

To examine convergent validity, the average variance extracted (AVE) of each variable was calculated. The AVE reflects the amount of variance in the items that is accounted for by the variables and indicates whether the items are sufficiently related to the variables. AVE values were above 0.50 or sufficiently close $(0.48$ and 0.49 ) to this threshold value. Given the overall good model fit and satisfactory values for internal reliability, these values are considered acceptable (Fornell and Larcker 1981). Finally, the Fornell and Larcker (1981) criterion demonstrated that for each variable, AVE is greater than the square of the correlation to other variables. These results provide evidence of discriminant validity, as they emphasize that the measurements used in this study are not only theoretically, but also empirically distinguishable.

\subsection{Results of ordinal regression analysis}

We estimated a heteroscedastic ordered logit model to test our hypotheses. We chose this method for the following reasons. First, the dependent variable, organizational agility, was calculated using Likert-type data, which is an ordinal measurement and therefore requires to fit an ordinal model. ${ }^{2}$ Second, we estimated this regression model to deal with heteroscedasticity. When an ordinal regression model incorrectly assumes that error variances are the same for all cases, the standard errors are wrong and the parameter estimates are biased (Williams 2009; Long and Freese 2014). A

\footnotetext{
${ }^{2}$ In a robustness test, we ran an OLS regression with heteroscedasticity-robust standard errors (which was suggested by a significant White's test for heteroscedasticity). The results with regard to the hypotheses were consistent with the results of the heteroscedastic ordered logit regression. Detailed results are available from the authors upon request.
} 


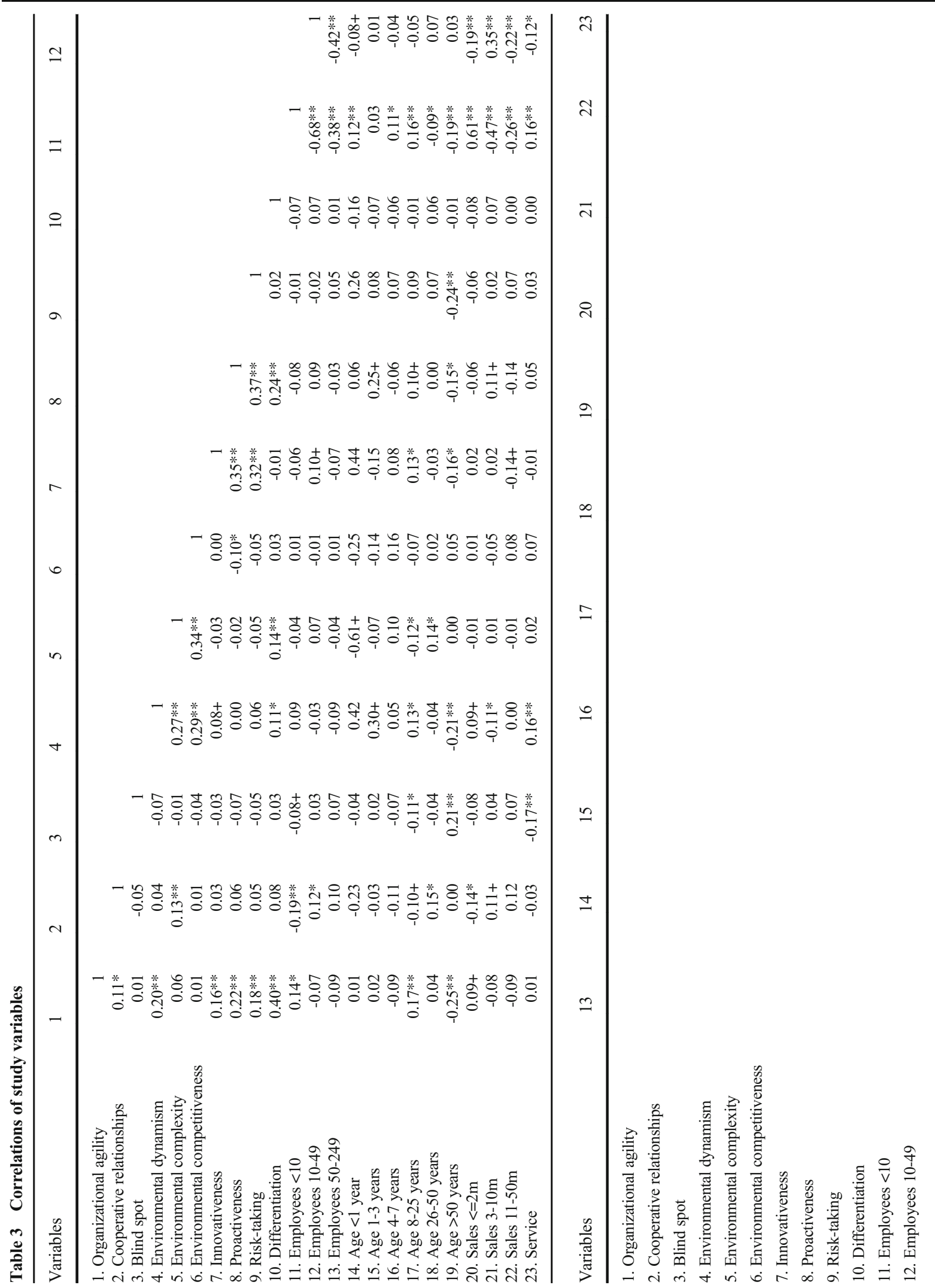




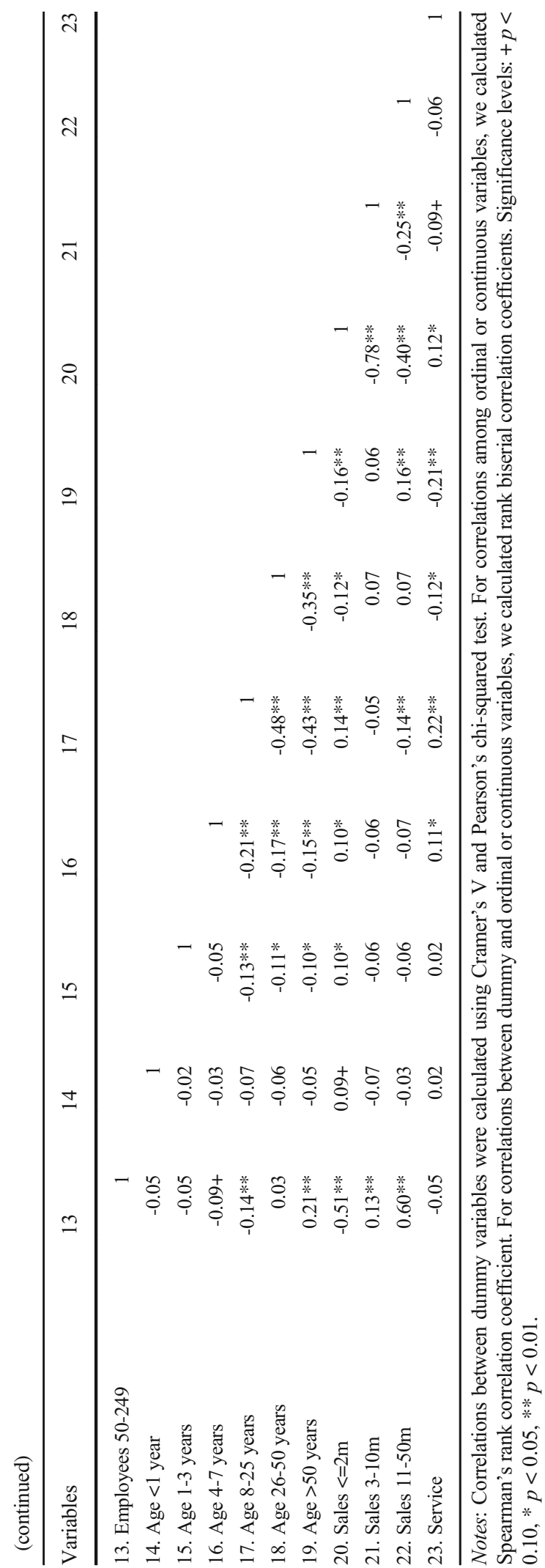

heteroscedastic ordered logit model includes equations for heteroscedasticity that specify the determinants of heteroscedasticity in an attempt to correct for it (Williams 2010).

Table 4 shows the results of the heteroscedastic ordered logit model. ${ }^{3}$

Model 1 serves as a baseline model and includes the control variables. Regarding the variables that describe a firm's external environment, only environmental dynamism shows a positive and significant coefficient. Among the variables describing the strategic posture of a firm, innovativeness, risk-taking and differentiation exhibit positive and significant coefficients. In terms of age, young SMEs (between 1 and 3 years) and more established SMEs (between 8 and 50 years) show a positive and significant coefficient. In Model 2, we add the independent variables cooperative relationships and blind spot. The results show a positive and significant coefficient for cooperative relationships, which supports a positive relationship between a SME's number of cooperative relationships and its organizational agility as proposed by Hypothesis 1. Model 3 then includes the interaction term of blind spot and cooperative relationships. The results show a negative and significant coefficient for the interaction term of blind spot and cooperative relationships. This result suggests no support for Hypothesis $2 \mathrm{~b}$ but lends preliminary support for Hypothesis $2 \mathrm{a}$ which proposes that the positive relationship between the number of cooperative relationships and organizational agility is stronger for SMEs located in agglomerations.

To further examine these effects, we calculated average marginal effects (Long and Freese 2014). The results suggest that SMEs with a greater number of cooperative relationships have significantly higher probabilities of showing strong organizational agility. For example, we find that, on average, if the number of cooperative relationships increases by 20 , the probabilities of entering the organizational agility categories 4 and 5 increase by 0.004 and 0.008 , respectively. This is offset by a decrease of 0.001 in the probability of entering category 2 and a 0.005 decrease of entering category 3 .

\footnotetext{
3 The model includes multi-item ordinal control variables. Results of a likelihood ratio chi-square test and BIC test suggested that treating these variables as continuous in the regression model was preferable to including them as categorical variables as this would allow to estimate a more parsimonious model (Long and Freese 2014). Results with regard to the hypotheses remain unchanged. Detailed results are available from the authors upon request.
} 
All effects are significant $(p<0.10$ or $p<0.01)$. These results ultimately lend support to Hypothesis 1 .

To further examine the interaction effect and test the alternative Hypotheses $2 \mathrm{a}$ and $2 \mathrm{~b}$, we tested whether the predictive margins of cooperative relationships for SMEs located in agglomerated hot spots and peripheral blind spots were significantly different from each other. We find that, in fact, they significantly differ from each other, but only for higher numbers of cooperative relationships (greater than 60). For these numbers, hot spot SMEs have significantly lower probabilities of entering lower organizational agility categories, but significantly higher probabilities of entering higher categories. Thus, the results suggest that SMEs located in agglomerations are more likely to show higher levels of organizational agility as the number of cooperative relationships increases compared to those SMEs located in peripheral areas. However, this effect is only significant for higher numbers of cooperative relationships. We therefore find partial support for Hypothesis 2a. The alternative Hypothesis $2 \mathrm{~b}$ is not supported.

In addition, we aimed at generating more nuanced insights into the relationship between a SME's number of cooperative relationships and its organizational agility. We therefore estimated separate heteroscedastic ordered logit models for each of the five items measuring organizational agility. Table 5 summarizes the results. We find positive and significant coefficients for cooperative relationships in four out of the five models. The results suggest a positive relationship between a SME's number of cooperative relationships and the ability to respond easily and quickly to changes in aggregate consumer demand, react to new product or service launches by the competitors, expand in new regional or international markets, and change the variety of products or services available for sale. The relationship between the number of cooperative relationships and the ability to easily and quickly customize products or services to suit an individual customer is not significant. One explanation for this insignificant finding might be that product or service customization does not necessarily involve a large number of partners but rather requires an effective and efficient interaction with the specific customer.

Moreover, we find negative and significant coefficients for the interaction term of blind spot and cooperative relationships in the same four models. The results suggest that for SMEs located in agglomerated areas, the positive relationship between cooperative relationships and the ability to respond easily and quickly to changes in demand, react to new product or service launches, expand in new regional or international markets, and change the variety of products or services is stronger compared to SMEs located in peripheral areas. This finding resonates with our theoretical reasoning proposing that within agglomerations, SMEs can choose the optimal cooperation partner from a large variety of potential partners and are capable of quickly absorbing relevant knowledge from the partners. These advantages allow them to create or adapt new products or services or to expand their operations more easily and more quickly. Again, the interaction term in the model predicting agility in terms of customizing products or services is not significant.

\subsection{Robustness checks}

We performed a number of tests to evaluate the robustness of the results. First, to ensure that the significance of the regression equation was not due solely to the control variables, we ran a step-wise ordinal regression model. The results revealed that all of the statistically significant variables reported in Table 4 entered and remained in the equation during the step-wise procedure.

Second, correlation statistics showed some significant results among the dummy variables controlling for age, number of employees, and sales, which could lead to unreliable and unstable estimates of regression coefficients. We therefore developed a reduced set of three dummy variables to avoid multicollinearity problems. These dummy variables were calculated in a way that captured the differences in the number of employees and sales between small (including micro) and mediumsized enterprises (European Commission 2015) and the differences in age between young and established firms (LiPuma et al. 2013). ${ }^{4}$ We then ran separate regressions with the full and the reduced set of control variables, even though VIF levels were well below 10 for all models. Results regarding the coefficients of the variables were consistent and robust.

Further, we tested for potential non-response and channel biases. Non-response bias was evaluated in two different ways. The first procedure draws on

\footnotetext{
${ }^{4}$ Reduced set of control variables: medium employees: 1: 50-249 employees, $0:<50$ employees; established firm: $1: \geq 8$ years, 0 : $<8$ years; medium sales: 1: 11-50 mEUR, $0: \leq 10$ mEUR.
} 
Table 4 Results of the heteroscedastic ordered logit model (dependent variable: organizational agility)

\begin{tabular}{|c|c|c|c|}
\hline Variable & Model 1 & Model 2 & Model 3 \\
\hline Cooperative relationships & & $\begin{array}{l}0.004 * * \\
(0.00)\end{array}$ & $\begin{array}{l}0.008 * * \\
(0.00)\end{array}$ \\
\hline Blind spot & & $\begin{array}{l}0.026 \\
(0.11)\end{array}$ & $\begin{array}{l}0.190 \\
(0.13)\end{array}$ \\
\hline Cooperative relationships $\mathrm{X}$ blind spot & & & $\begin{array}{l}-0.007 * * \\
(0.00)\end{array}$ \\
\hline Environmental dynamism & $\begin{array}{l}0.121 * \\
(0.05)\end{array}$ & $\begin{array}{l}0.129 * \\
(0.05)\end{array}$ & $\begin{array}{l}0.101+ \\
(0.05)\end{array}$ \\
\hline Environmental complexity & $\begin{array}{l}0.052 \\
(0.01)\end{array}$ & $\begin{array}{l}0.040 \\
(0.06)\end{array}$ & $\begin{array}{l}0.041 \\
(0.06)\end{array}$ \\
\hline Environmental competitiveness & $\begin{array}{l}-0.004 \\
(0.07)\end{array}$ & $\begin{array}{l}-0.012 \\
(0.06)\end{array}$ & $\begin{array}{l}-0.016 \\
(0.06)\end{array}$ \\
\hline Innovativeness & $\begin{array}{l}0.140+ \\
(0.07)\end{array}$ & $\begin{array}{l}0.147 * \\
(0.07)\end{array}$ & $\begin{array}{l}0.156^{*} \\
(0.07)\end{array}$ \\
\hline Proactiveness & $\begin{array}{l}0.042 \\
(0.07)\end{array}$ & $\begin{array}{l}0.029 \\
(0.07)\end{array}$ & $\begin{array}{l}0.031 \\
(0.07)\end{array}$ \\
\hline Risk-taking & $\begin{array}{l}0.192 * * \\
(0.07)\end{array}$ & $\begin{array}{l}0.182 * * \\
(0.07)\end{array}$ & $\begin{array}{l}0.183^{* * *} \\
(0.07)\end{array}$ \\
\hline Differentiation & $\begin{array}{l}0.933^{* *} \\
(0.16)\end{array}$ & $\begin{array}{l}0.910 * * \\
(0.16)\end{array}$ & $\begin{array}{l}0.927 \text { ** } \\
(0.16)\end{array}$ \\
\hline Employees $<10$ & $\begin{array}{l}0.145 \\
(0.23)\end{array}$ & $\begin{array}{l}0.178 \\
(0.22)\end{array}$ & $\begin{array}{l}0.149 \\
(0.22)\end{array}$ \\
\hline Employees 10-49 & $\begin{array}{l}-0.123 \\
(0.19)\end{array}$ & $\begin{array}{l}-0.143 \\
(0.19)\end{array}$ & $\begin{array}{l}-0.190 \\
(0.19)\end{array}$ \\
\hline Age $<1$ year & $\begin{array}{l}-0.162 \\
(0.75)\end{array}$ & $\begin{array}{l}-0.215 \\
(0.73)\end{array}$ & $\begin{array}{l}-0.166 \\
(0.73)\end{array}$ \\
\hline Age $1-3$ years & $\begin{array}{l}0.670+ \\
(0.36)\end{array}$ & $\begin{array}{l}0.631+ \\
(0.35)\end{array}$ & $\begin{array}{l}0.596+ \\
(0.35)\end{array}$ \\
\hline Age 4-7 years & $\begin{array}{l}0.073 \\
(0.24)\end{array}$ & $\begin{array}{l}0.082 \\
(0.24)\end{array}$ & $\begin{array}{l}0.065 \\
(0.23)\end{array}$ \\
\hline Age $8-25$ years & $\begin{array}{l}0.402 * \\
(0.17)\end{array}$ & $\begin{array}{l}0.394 * \\
(0.16)\end{array}$ & $\begin{array}{l}0.402 * \\
(0.16)\end{array}$ \\
\hline Age $26-50$ years & $\begin{array}{l}0.295+ \\
(0.16)\end{array}$ & $\begin{array}{l}0.266+ \\
(0.16)\end{array}$ & $\begin{array}{l}0.274+ \\
(0.16)\end{array}$ \\
\hline Sales $\leq 2 \mathrm{~m}$ & $\begin{array}{l}0.160 \\
(0.25)\end{array}$ & $\begin{array}{l}0.230 \\
(0.25)\end{array}$ & $\begin{array}{l}0.167 \\
(0.24)\end{array}$ \\
\hline Sales $3-10 \mathrm{~m}$ & $\begin{array}{l}-0.032 \\
(0.22)\end{array}$ & $\begin{array}{l}0.041 \\
(0.22)\end{array}$ & $\begin{array}{l}-0.029 \\
(0.22)\end{array}$ \\
\hline Service & $\begin{array}{l}-0.096 \\
(0.12)\end{array}$ & $\begin{array}{l}-0.091 \\
(0.12)\end{array}$ & $\begin{array}{l}-0.066 \\
(0.12)\end{array}$ \\
\hline$N$ & 434 & 434 & 434 \\
\hline $\begin{array}{l}\text { Log likelihood } \\
\text { LR chi2 }\end{array}$ & $\begin{array}{l}-1082.84 \\
L R \operatorname{chi} 2(19)=155.25^{* *}\end{array}$ & $\begin{array}{l}-1076.71 \\
\operatorname{LR} \operatorname{chi} 2(21)=167.51 * *\end{array}$ & $\begin{array}{l}-1072.03 \\
\text { LR } \operatorname{chi} 2(22)=176.88 * *\end{array}$ \\
\hline
\end{tabular}

Numbers in parentheses are standard errors. Significance levels: $+p<0.10, * p<0.05, * * p<0.01$

Armstrong and Overton (1977), who argued that the profile of late respondents is similar to that of nonrespondents. We compared the means, medians, and proportions of the frame variables and key survey variables of early versus late respondents. Frame variables included the control variables and key survey variables encompassed all variables included in the hypotheses. Given that we did not find significant 
Table 5 Summary of the results of the heteroscedastic ordered logit model (dependent variable: single item of organizational agility)

\begin{tabular}{|c|c|c|c|c|c|}
\hline \multirow[b]{2}{*}{ Variable } & \multicolumn{5}{|c|}{ Organizational agility in terms of ... } \\
\hline & $\begin{array}{l}\text { response to changes } \\
\text { in demand }\end{array}$ & $\begin{array}{l}\text { product/service } \\
\text { customization }\end{array}$ & $\begin{array}{l}\text { reaction to product/ } \\
\text { service launches }\end{array}$ & $\begin{array}{l}\text { regional or } \\
\text { international } \\
\text { expansion }\end{array}$ & $\begin{array}{l}\text { changes in product/ } \\
\text { service variety }\end{array}$ \\
\hline $\begin{array}{l}\text { Cooperative } \\
\text { relationships }\end{array}$ & $\begin{array}{l}0.005^{*} \\
(0.003)\end{array}$ & $\begin{array}{l}0.002 \\
(0.002)\end{array}$ & $\begin{array}{l}0.009 * \\
(0.003)\end{array}$ & $\begin{array}{l}0.014 * * \\
(0.004)\end{array}$ & $\begin{array}{l}0.007 * \\
(0.003)\end{array}$ \\
\hline $\begin{array}{l}\text { Cooperative } \\
\text { relationships X blind } \\
\text { spot }\end{array}$ & $\begin{array}{l}-0.005+ \\
(0.003)\end{array}$ & $\begin{array}{l}-0.001 \\
(0.003)\end{array}$ & $\begin{array}{l}-0.008^{*} \\
(0.004)\end{array}$ & $\begin{array}{l}-0.012 * \\
(0.005)\end{array}$ & $\begin{array}{l}-0.006+ \\
(0.003)\end{array}$ \\
\hline$N$ & 433 & 434 & 434 & 432 & 432 \\
\hline Log likelihood & -572.11 & -421.14 & -547.56 & -611.68 & -564.42 \\
\hline LR chi2(22) & $96.16^{* *}$ & $122.47 * *$ & $121.95 * *$ & $91.13 * *$ & $112.69 * *$ \\
\hline
\end{tabular}

Numbers in parentheses are standard errors. Significance levels: $+p<0.10, * p<0.05, * * p<0.01$

differences on any of the variables $(p>0.1)$, the analysis suggested that non-respondents did not differ from respondents. In a second step, we collected secondary data on the frame variables and firm location of a randomly selected subset $(n=1500)$ of non-respondents to evaluate non-response bias based on available information on actual non-respondents (Rogelberg and Stanton 2007; Lohr et al. 2016). Non-respondents did not differ significantly $(p>0.1)$ from respondents in terms of most of these variables, with the exception of (weakly) significant results for the number of employees $(p=0.09)$ and sales $(p=0.09)$. Taken as a whole, results from these additional analyses support our previous findings that non-response bias is not an issue in our data since the observed differences are not systematically related to the key survey variables. Furthermore, we tested for channel bias that could be present due to different response modes as we offered the options of replying via the webbased survey or via postal mailing. We compared the means, medians, and proportions of the frame variables and the key survey variables of the responses received via web-based survey $(n=367)$ and the responses received via the paper-based version $(n=73)$. Since the only significant difference $(p=0.04)$ was that firms located in hot spots provided their responses more often via the web-based survey and less often via postal mailing as compared to firms located in blind spots, we conclude that the response mode does not notably bias the results and the conclusions of the study.

Finally, we tried to rule out substantial effects of common method variance by using both procedural and statistical approaches (e.g., Podsakoff et al. 2003; Conway and Lance 2010). For example, in the design of the survey instrument, we carefully formulated and pretested the items to avoid conceptual overlap in items for different variables. In addition, we separated the criterion variable from predictor variables and counterbalanced sets of items to diminish the effects of consistency artifacts. We then used random assignment of respondents to different item orders (for both the web-based and the paper-based questionnaire). We also guaranteed anonymity to the respondents. With respect to statistical approaches, we demonstrated the construct validity of our study variables (see section 4.1) (Conway and Lance 2010). We also ran a Harman's one-factor test to statistically control for common method variance (Harman 1976). The variables entered into the analysis do not form only one factor with eigenvalue higher than one, and the variance does not merely stem from one factor when all variables are loaded onto it. Although the threat of common method bias can never be fully ruled out, the procedural methods and the statistical results made us confident that it did not predominantly drive our findings.

\section{Discussion and implications}

In this paper, we set out to investigate from a contingency perspective whether SMEs in different locational environments benefit from cooperative relationships in terms of greater abilities to detect changes in the business environment and react flexibly. Specifically, we hypothesized that cooperating with partner firms ensures SMEs' access to complementary resources needed for any adaptation or reaction to environmental or 
technological changes and that cooperation can therefore serve as an adequate strategy for SMEs to increase their organizational agility. Concerning the role of the locational environment, contingency theory literature led us to formulate alternative hypotheses arguing that the relationship between cooperative relationships and agility is stronger either for SMEs located in agglomerations owing to agglomeration economies or for SMEs located in peripheral locations owing to their distinct dependence on additional resources. Our findings confirmed our first hypothesis and suggested that a SME's greater number of cooperative relationships is indeed positively associated with stronger organizational agility. Taking the role of location into account, we found this relationship to be stronger for SMEs located in agglomerations and weaker for SMEs located in peripheral areas, although this result is only significant for higher numbers of cooperative relationships.

Our findings add to the current body of knowledge in various ways. We not only extend the limited literature on the antecedents of organizational agility, but also clarify some of the conditionality of the findings of prior literature (e.g., Yusuf et al. 2014). Our study's results show a picture of SMEs benefiting from spatial co-location in agglomerations through multiple cooperative relationships that assist them in enhancing their ability to adapt to the ever-changing business environment. At first glance, this finding appears to be counterintuitive. Cooperation pays off not in peripheral locations, where locational quality is low and returns from cooperative relationships in terms of access to resources, for example, appear to be high (Dicken and Lloyd 1990; Westhead et al. 2004; Payne et al. 2009), but in already dense and interconnected agglomerations. Results suggest that a dichotomous reflection on the question of where SMEs locate falls short. The postulated dichotomy of SMEs locating either in an agglomeration as a reaction to peripheral disadvantages or in the periphery as a reaction to agglomeration disadvantages does not seem to hold. Instead of relocating when rigidities and other agglomeration diseconomies become stronger, SMEs can counter such agglomeration diseconomies by seizing various opportunities to cooperate. The results of this research thus shed light on a self-reinforcing inner strength of agglomerations that has not previously been elaborated. The inner strength of agglomerations allows SMEs to overcome potential diseconomies and makes the location even more vibrant.
Our findings address the concerns that agglomerations are unfavorable locational environments since they develop a homogeneous macroculture (e.g., Pouder and St. John 1996). This homogeneous macroculture is said to originate from converging mental models of firm managers, suppressing innovation and increasing rigidity owing to organizational inertia, mimetic behavior, myopic competitive practices, and overspecialization of agglomerated firms (e.g., Pouder and St. John 1996). While these concerns are certainly valid, this study demonstrates that agglomerations can provide a remedy for these threats. Our findings support the view that agglomerated regions offer various opportunities for cooperation and are vibrant and dynamic environments, enhancing the ability of incumbent companies to react flexibly to new challenges and proactively drive the external environment.

Further, previous research discusses positive versus negative agglomeration effects based on outcomes like survival or entry rates as a result of locational conditions (e.g., Shaver and Flyer 2000; Alcácer and Chung 2007). We add to more recent contributions (e.g., Galbraith et al. 2008) that have begun exploring under which conditions spatial co-location is advantageous. We discuss whether and how firms use characteristics embedded in their surroundings, such as cooperative relationships with other companies, to shape effective and agile organizing strategies. We contribute to shifting the perspective from an outcome-oriented discussion to a contingency-oriented discussion of organizational moves in different external environments. This perspective shows that for high numbers of cooperative relationships, the association of a cooperation-based strategy and agility is stronger for SMEs located in an agglomeration than for those located in a peripheral area. These results lead us to conclude that in the light of potential agglomeration diseconomies, SMEs could consider relational investments in their organizational agility to be a counterweight to these diseconomies, in particular to the risks of overspecialization and technological lock-in. SMEs can prevent being negatively affected by these risks by actively keeping themselves agile through accumulating and absorbing external knowledge gained in cooperative relationships. This interpretation resonates with findings from prior research suggesting that firms located in agglomerations should consciously cultivate their cooperative relationships, especially those with distant partners, to neutralize the tendencies for lock-in inherent and to avoid a 
weakening of learning abilities and innovation capacity (Giuliani and Bell 2005; Coombs et al. 2009).

Lastly, this study contributes to the SME literature. Compared with large corporations, SMEs are typically leaner and more flexible, but at the same time more vulnerable in a competitive business environment (Arbussa et al. 2017). One reason for this higher vulnerability is that resource limitations hinder SMEs in driving their external environment and reacting flexibly to customer demands, competitive moves, or other environmental changes (Chan et al. 2019). These challenges, however, may be mitigated by a cooperation-based strategy that allows SMEs to gain access to necessary resources and capabilities. In this study, we utilize the unique research context of SMEs to show that these firms particularly leverage such cooperative relationships. To profit from the local dynamism created by external economies of scale in agglomerations, SMEs depend even more on access to external sources to accumulate technological or managerial knowledge (Chun and Mun 2012). While large, vertically integrated corporations benefit from internal economies of scale and are more likely to generate the resources that are required to be agile inside the firm, it seems to be an effective strategy for SMEs to partner with others to survive under environmental uncertainty and rapid technological obsolescence. These results, together with the findings from prior research, make us believe that the positive relationship between cooperative relationships and organizational agility, as found in this study, is stronger for SMEs than for large corporations or even unique to the SME context.

Our study also has practical implications. SMEs located in agglomerations seem to benefit from cooperative relationships in terms of an increase in agility. However, managers of these SMEs should not wait passively for agglomeration economies to boost firm performance and must anticipate being affected by agglomeration diseconomies. Our results show that the locational environment of a SMEs is a contextual factor that determines the setting in which the firm operates and strategic decisions are made, but it does not directly affect strategic decisions or the related outcomes. Therefore, managers of SMEs located within a bountiful environment of high locational quality should actively seek and make use of the manifold cooperation opportunities and initiate cooperative relationships. These relationships enable them to act in an agile way, with agility being an important counterweight to agglomeration diseconomies such as organizational inertia and rigidity. Our findings underline that entering into cooperative relationships presents an effective strategy to hedge against the risks associated with agglomeration diseconomies.

\section{Conclusion and limitations}

This study's main focus was on answering the question of whether cooperating with others is an adequate strategy for SMEs to enhance their organizational agility, exploring the locational environment of the firm as a contingency factor. Results revealed that a greater number of cooperative relationships is in fact positively associated with SMEs' organizational agility. This effect is stronger for agglomerated than for peripheral SMEs when the number of cooperative relationships is high, which adds to the rationale suggesting that within the analyzed context, agglomerated SMEs can seize the abundant opportunities to cooperate in order to counter agglomeration diseconomies such as organizational inertia, mimetic behavior, and myopic competitive practices. SMEs can prevent being negatively affected by these risks by actively keeping themselves agile through accumulating and absorbing external knowledge gained in cooperative relationships.

Our study has several limitations. First, our data are cross-sectional, which limits our ability to observe the actual causal effect of how inter-firm cooperative relationships enable firms to proactively drive and react to environmental change or to investigate the ease and speed with which such strategic actions occur. Future research could examine the relationship between cooperative relationships and firms' agility, capturing agility by selected strategic actions such as the adaptation of product lines and the recombination of business units (Albert 2018), ideally in a longitudinal setting. Particularly interesting might be the study of how cooperation fosters SMEs' agility over time, whether the moderating impact of location remains stable, or whether companies adapt their strategic actions to better fit the environmental context, be it an agglomerated or peripheral setting.

Second, our study captures the number of cooperative relationships but does not disentangle further effects of the structure or content of such relationships. Such analyses would allow for a refinement of our results, for example regarding the effects of equity versus nonequity cooperation (e.g., Ripollés and Blesa 2019) or $\mathrm{R} \& \mathrm{D}$ versus marketing and manufacturing cooperation (Chun and Mun 2012; Radicic et al. 2018). 
Finally, we conducted our study within a specific regional context and investigated the hypotheses using a sample that represents small and medium-sized enterprises operating in the 22 key technology sectors in Bavaria. The generalizability of our results is therefore restricted by the specifics of the regional research setting (e.g., taxes, legislation, technology, regional public policies). Nevertheless, limiting the geographic focus has been postulated to be of critical importance for regional comparative studies (e.g., Furman 2003; Lublinski 2003) and therefore was a mandatory decision to be made in this study. In addition, the limitations associated with a specific geographic focus confirm the suggestions of prior research that results of location studies often cannot be fully transported across regional contexts (e.g., Alcácer 2006; Findikoglu and Watson-Manheim 2015). Future studies should therefore extend this research to other locations to enhance the generalizability of the findings.

Acknowledgements We are very grateful to Leon Schjoedt and two anonymous reviewers for their helpful comments and suggestions. We would also like to thank Robert Pfeffer for his excellent research assistance throughout this project.

Funding Open Access funding enabled and organized by Projekt DEAL.

\section{Appendix. Results of factor analysis}

Table 6

Loading

Organizational agility (Cronbach's alpha $=0.76, \mathrm{CR}=0.82$, AVE $=0.48$ )

How easily and quickly can your firm perform the following actions?

Respond to changes in aggregate consumer demand

Customize a product or service to suit an individual customer

React to new product or service launched by competitors

Expand into new regional or international markets

Change (i.e., expand or reduce) the variety of products / services available for sale

Environmental complexity (Cronbach's alpha $=0.87, \mathrm{CR}=0.89$, AVE $=0.63$ )

The activities of our firm influence the outcomes of 0.65 (continued)

\begin{tabular}{lc}
\hline & Loading \\
\hline $\begin{array}{l}\text { Co-located firms depend on our firm to effectively } \\
\text { perform its tasks in order to continue performing their }\end{array}$ & 0.75 \\
own tasks effectively. & \\
Work in our firm is connected to the work of co-located & 0.86 \\
$\quad$ firms. & 0.84 \\
$\begin{array}{l}\text { Our firm depends on the effective functioning of } \\
\text { co-located firms to keep performing its own tasks }\end{array}$ & \\
effectively. & \\
The activities of co-located firms influence the & 0.83 \\
$\quad$ outcomes of our firm. & \\
Environmental competitiveness (Cronbach's alpha $=0.59$, \\
$\quad$ CR $=0.77$, AVE = 0.63)
\end{tabular}

Competition in our region is more intense than in other regions.

Our firm has relatively strong competitors.

Environmental dynamism

In our local business environment, technological, economic and cultural changes are taking place fast and often.

Innovativeness (Cronbach's alpha $=0.69, \mathrm{CR}=0.77$, $\mathrm{AVE}=0.53$ )

In general, the top managers of my firm favor a strong emphasis on R\&D, technological leadership and innovation versus a strong emphasis on the marketing of true and tried products or services.

During the past 3 years our firm has marketed, excluding mere minor variations, no new lines of products or services versus very many new lines of products or services

During the past 3 years, changes in product and service lines have been dramatic versus changes in product and service lines have been of a minor nature.

Proactiveness (Cronbach's alpha $=0.65, \mathrm{CR}=0.76, \mathrm{AVE}=0.62$ )

In our firm, there is a strong tendency to follow competitors in introducing new things and ideas versus we always try to be ahead competitors in product novelty or speed of innovation and usually succeed.

Our firm is characterized by the fact that we favor the tried and true versus that we are growth, innovation, and development oriented.

Risk-taking (Cronbach's alpha $=0.79, \mathrm{CR}=0.84, \mathrm{AVE}=0.64$ )

Our firm typically seeks to avoid competitive clashes, preferring a 'live-and-let-live' posture versus our firm typically adopts a very competitive

'undo-the-competitors' posture.

In general, the top managers of my firm have a strong proclivity for low risk projects (with normal and certain rates of return) versus a strong proclivity for high risk projects (with chances of very high returns).

In general, the top managers of my firm believe that owing to the nature of the environment, it is best to explore it gradually via timid, incremental behavior versus bold, wide-ranging acts are necessary to achieve the firm's objectives. 
(continued)

Loading

Differentiation (Cronbach's alpha $=0.71, \mathrm{CR}=0.78, \mathrm{AVE}=0.49$ )

To what extent do you agree to the following statements? Over the last five years, the following factors were a source of competitive advantage for our firm:

Product quality/design

0.66

Professional/technical skills

Established reputation

Quality of service for customers

$C R$ composite reliability, $A V E$ average variance extracted. All items were measured on a five-point scale, anchored by $1=$ strongly disagree and $5=$ strongly agree

Open Access This article is licensed under a Creative Commons Attribution 4.0 International License, which permits use, sharing, adaptation, distribution and reproduction in any medium or format, as long as you give appropriate credit to the original author(s) and the source, provide a link to the Creative Commons licence, and indicate if changes were made. The images or other third party material in this article are included in the article's Creative Commons licence, unless indicated otherwise in a credit line to the material. If material is not included in the article's Creative Commons licence and your intended use is not permitted by statutory regulation or exceeds the permitted use, you will need to obtain permission directly from the copyright holder. To view a copy of this licence, visit http://creativecommons.org/licenses/by/4.0/.

\section{References}

Acs, Z. J. (Ed.). (1999). Are small firms important? Their role and impact. Boston: Kluwer Academic Publishers.

Acs, Z. J., Audretsch, D. B., \& Feldman, M. P. (1994). R\&D spillovers and recipient firm size. Review of Economics and Statistics, 76(2), 336-340. https://doi.org/10.2307/2109888.

Albert, D. (2018). Organizational module design and architectural inertia: evidence from structural recombination of business divisions. Organization Science, 29(5), 890-911. https://doi. org/10.1287/orsc.2018.1210.

Alcácer, J. (2006). Location choices across the value chain: how activity and capability influence collaboration. Management Science, 52(10), 1457-1471. https://doi.org/10.1287 /mnsc. 1060.0658 .

Alcácer, J., \& Chung, W. (2007). Location strategies and knowledge spillovers. Management Science, 53(5), 760-776. https://doi.org/10.1287/mnsc.1060.0637.

Almeida, P., \& Kogut, B. (1997). The exploration of technological diversity and the geographic localization of innovation. Small Business Economics, 9(1), 21-31. https://doi.org/10.1023 /A:1007995512597.

Amorós, J. E., Felzensztein, C., \& Gimmon, E. (2013). Entrepreneurial opportunities in peripheral versus core regions in Chile. Small Business Economics, 40(1), 119139. https://doi.org/10.1007/s11187-011-9349-0.

Arbussa, A., Bikfalvi, A., \& Marquès, P. (2017). Strategic agilitydriven business model renewal: the case of an SME. Management Decision, 55(2), 271-293. https://doi. org/10.1108/MD-05-2016-0355.

Arikan, A. T., \& Schilling, M. A. (2011). Structure and governance in industrial districts: implications for competitive advantage. Journal of Management Studies, 48(4), 772803. https://doi.org/10.1111/j.1467-6486.2010.00951.x.

Armstrong, J. S., \& Overton, T. S. (1977). Estimating nonresponse bias in mail surveys. Journal of Marketing Research, 14(3), 396-402. https://doi.org/10.1177/002224377701400320.

Baptista, R., \& Swann, P. (1998). Do firms in clusters innovate more? Research Policy, 27(5), 525-540. https://doi. org/10.1016/S0048-7333(98)00065-1.

Barney, J. (1991). Firm resources and sustained competitive advantage. Journal of Management, 17(1), 99-120. https://doi. org/10.1177/014920639101700108.

Bathelt, H., Malmberg, A., \& Maskell, P. (2004). Clusters and knowledge: local buzz, global pipelines and the process of knowledge creation. Progress in Human Geography, 28(1), 31-56. https://doi.org/10.1191/0309132504ph469oa.

Berchicci, L., King, A., \& Tucci, C. L. (2011). Does the apple always fall close to the tree? The geographical proximity choice of spin-outs. Strategic Entrepreneurship Journal, 5(2), 120-136. https://doi.org/10.1002/sej.110.

Bi, R., Davison, R., \& Smyrnios, K. (2018). The role of top management participation and IT capability in developing SMEs' competitive process capabilities. Journal of Small Business Management, 57(3), 1008-1026. https://doi. org/10.1111/jsbm.12380.

Chakravarty, A., Grewal, R., \& Sambamurthy, V. (2013). Information technology competencies, organizational agility, and firm performance: enabling and facilitating roles. Information Systems Research, 24(4), 976-997. https://doi. org/10.1287/isre.2013.0500.

Chan, C. M. L., Teoh, S. Y., Yeow, A., \& Pan, G. (2019). Agility in responding to disruptive digital innovation: case study of an SME. Information Systems Journal, 29(2), 436-455. https://doi.org/10.1111/isj.12215.

Chun, H., \& Mun, S. B. (2012). Determinants of R\&D cooperation in small and medium-sized enterprises. Small Business Economics, 39(2), 419-436. https://doi.org/10.1007 /s11187-010-9312-5.

Cohen, W. M., \& Levinthal, D. A. (1990). Absorptive capacity: a new perspective on learning and innovation. Administrative Science Quarterly, 35(1), 128-152. https://doi.org/10.2307 12393553.

Colombo, M. G., Grilli, L., \& Piva, E. (2006). In search of complementary assets: the determinants of alliance formation of high-tech start-ups. Research Policy, 35(8), 1166-1199. https://doi.org/10.1016/j.respol.2006.09.002.

Conway, J. M., \& Lance, C. E. (2010). What reviewers should expect from authors regarding common method bias in organizational research. Journal of Business and Psychology, 25(3), 325-334. https://doi.org/10.1007/s10869-010-9181-6.

Coombs, J. E., Deeds, D. L., \& Duane Ireland, R. (2009). Placing the choice between exploration and exploitation in context: a study of geography and new product development. Strategic 
Entrepreneurship Journal, 3(3), 261-279. https://doi. org/10.1002/sej.74.

Covin, J. G., \& Slevin, D. P. (1989). Strategic management of small firms in hostile and benign environments. Strategic Management Journal, 10(1), 75-87. https://doi.org/10.1002 /smj.4250100107.

Das, T. K., \& Teng, B. S. (2000). A resource-based theory of strategic alliances. Journal of Management, 26(1), 31-61. https://doi.org/10.1016/S0149-2063(99)00037-9.

Dicken, P., \& Lloyd, P. E. (1990). Location in space: theoretical perspectives in economic geography (3rd ed.). New York: Harper Collins.

Doz, Y. L., \& Kosonen, M. (2008). The dynamics of strategic agility: Nokia's rollercoaster experience. California Management Review, 50(3), 95-118. https://doi. org/10.2307/41166447.

European Commission. (2015). User guide to the SME definition. Luxemburg: Publications Office of the European Union. https://doi.org/10.2873/620234.

Findikoglu, M. N., \& Watson-Manheim, M. B. (2015). Do small and medium-sized IT firms form service partnerships with nonlocal IT firms? An assessment of facilitators. Journal of Small Business Management, 53(4), 986-1010. https://doi. org/10.1111/jsbm.12117.

Fornell, C., \& Larcker, D. F. (1981). Evaluating structural equation models with unobservable variables and measurement error. Journal of Marketing Research, 18(1), 39-50. https://doi.org/10.2307/3151312.

Furman, J. L. (2003). Location and organizing strategy: exploring the influence of location on the Organization of Pharmaceutical Research. In J. A. C. Baum \& O. Sorenson (Eds.), Advances in strategic management (pp. 49-88). Oxford: JAI/Elsevier. https://doi.org/10.1016/S0742-3322 (03)20002-4.

Galbraith, C. S., Rodriguez, C. L., \& DeNoble, A. F. (2008). SME competitive strategy and location behavior: an exploratory study of high-technology manufacturing. Journal of Small Business Management, 46(2), 183-202. https://doi. org/10.1111/j.1540-627X.2008.00239.x.

Galbraith, J. R. (1973). Designing complex organizations. Reading: Addison-Wesley.

Gherhes, C., Vorley, T., \& Williams, N. (2018). Entrepreneurship and local economic resilience: the impact of institutional hysteresis in peripheral places. Small Business Economics, 51(3), 577-590. https://doi.org/10.1007/s11187-017-9946-7.

Giuliani, E., \& Bell, M. (2005). The micro-determinants of mesolevel learning and innovation: evidence from a Chilean wine cluster. Research Policy, 34(1), 47-68. https://doi. org/10.1016/j.respol.2004.10.008.

Gligor, D. M., Holcomb, M. C., \& Stank, T. P. (2013). A multidisciplinary approach to supply chain agility: conceptualization and scale development. Journal of Business Logistics, 34(2), 94-108. https://doi.org/10.1111/jbl.12012.

Gnyawali, D. R., \& Park, B. J. (2009). Co-opetition and technological innovation in small and medium-sized enterprises: a multilevel conceptual model. Journal of Small Business Management, 47(3), 308-330. https://doi.org/10.1111 j.1540-627X.2009.00273.x.

Gordon, I. R., \& McCann, P. (2000). Industrial clusters: complexes, agglomeration and/or social networks? Urban
Studies, 37(3), 513-532. https://doi.org/10.1080 /0042098002096.

Gulati, R. (1998). Alliances and networks. Strategic Management Journal, 19(4), 293-317. https://doi.org/10.1002 /(SICI)1097-0266(199804)19:4<293::AID-SMJ982>3.0. $\mathrm{CO} ; 2-\mathrm{M}$.

Harman, H. H. (1976). Modern factor analysis (3rd ed.). Chicago: University of Chicago Press.

Hoffmann, W. H., \& Schlosser, R. (2001). Success factors of strategic alliances in small and medium-sized enterprisesan empirical survey. Long Range Planning, 34(3), 357-381. https://doi.org/10.1016/S0024-6301(01)00041-3.

Jansen, J. J. P., Van Den Bosch, F. A. J., \& Volberda, H. W. (2006). Exploratory innovation, exploitative innovation, and performance: effects of organizational antecedents and environmental moderators. Management Science, 52(11), 16611674. https://doi.org/10.1287/mnsc.1060.0576.

Kalnins, A., \& Chung, W. (2004). Resource-seeking agglomeration: a study of market entry in the lodging industry. Strategic Management Journal, 25(7), 689-699. https://doi. org/10.1002/smj.403.

Kukalis, S. (2010). Agglomeration economies and firm performance: the case of industry clusters. Journal of Management, $36(2), 453-481$. https://doi.org/10.1177 /0149206308329964.

Kumar, N., Stern, L. W., \& Anderson, J. C. (1993). Conducting interorganizational research using key informants. Academy of Management Journal, 36(6), 1633-1651. https://doi. org/10.5465/256824.

Lavie, D. (2006). The competitive advantage of interconnected firms: an extension of the resource-based view. Academy of Management Review, 31(3), 638-658. https://doi. org/10.5465/amr.2006.21318922.

Leitner, K.-H., \& Güldenberg, S. (2010). Generic strategies and firm performance in SMEs: a longitudinal study of Austrian SMEs. Small Business Economics, 35(2), 169-189. https://doi.org/10.1007/s11187-009-9239-x.

Lim, M. K., Mak, H.-Y., \& Shen, Z.-J. M. (2017). Agility and proximity considerations in supply chain design. Management Science, 63(4), 1026-1041. https://doi. org/10.1287/mnsc.2015.2380.

LiPuma, J. A., Newbert, S. L., \& Doh, J. P. (2013). The effect of institutional quality on firm export performance in emerging economies: a contingency model of firm age and size. Small Business Economics, 40(4), 817-841. https://doi. org/10.1007/s11187-011-9395-7.

Lohr, S. L., Riddles, M. K., \& Morganstein, D. (2016). Test for evaluating nonresponse bias in surveys. Survey Methodology, 42(2), 195-218.

Long, J. S., \& Freese, J. (2014). Regression models for categorical dependent variables using Stata. College Station, TX: Stata Press.

Lu, Y., \& Ramamurthy, K. (2011). Understanding the link between information technology capability and organizational agility: an empirical examination. MIS Quarterly, 35(4), 931-954. https://doi.org/10.2307/41409967.

Lublinski, A. E. (2003). Does geographic proximity matter? Evidence from clustered and non-clustered aeronautic firms in Germany. Regional Studies, 37(5), 453-467. https://doi. org/10.1080/0034340032000089031. 
Maskell, P. (2001). Towards a knowledge-based theory of the geographical cluster. Industrial and Corporate Change, 10(4), 921-943. https://doi.org/10.1093/icc/10.4.921.

McCann, B. T., \& Folta, T. B. (2008). Location matters: where we have been and where we might go in agglomeration research. Journal of Management, 34(3), 532-565. https://doi. org/10.1177/0149206308316057.

McCann, B. T., \& Folta, T. B. (2011). Performance differentials within geographic clusters. Journal of Business Venturing, 26(1), 104-123. https://doi.org/10.1016/j. jbusvent.2009.04.004.

Miller, D. (1983). The correlates of entrepreneurship in three types of firms. Management Science, 29(7), 770-791. https://doi. org/10.1287/mnsc.29.7.770.

Naudé, P., Zaefarian, G., Tavani, Z. N., Neghabi, S., \& Zaefarian, R. (2014). The influence of network effects on SME performance. Industrial Marketing Management, 43(4), 630-641. https://doi.org/10.1016/j.indmarman.2014.02.004.

Nemkova, E. (2017). The impact of agility on the market performance of born-global firms: an exploratory study of the 'Tech City' innovation cluster. Journal of Business Research, 80, 257-265. https://doi.org/10.1016/j. jbusres.2017.04.017.

Newbert, S. L., \& Tornikoski, E. T. (2012). Supporter networks and network growth: a contingency model of organizational emergence. Small Business Economics, 39(1), 141-159. https://doi.org/10.1007/s11187-010-9300-9.

O’Donnell, S. W. (2000). Managing foreign subsidiaries: agents of headquarters, or an interdependent network. Strategic Management Journal, 21(5), 525-548. https://doi. org/10.1002/(SICI)1097-0266(200005)21:5<525::AIDSMJ104>3.0.CO;2-Q.

Partanen, J., Kauppila, O.-P., Sepulveda, F., \& Gabrielsson, M. (2018). Turning strategic network resources into performance: the mediating role of network identity of small- and medium-sized enterprises. Strategic Entrepreneurship Journal. https://doi.org/10.1002/sej.1296.

Patterson, H., \& Anderson, D. (2003). What is really different about rural and urban firms? Some evidence from Northern Ireland. Journal of Rural Studies, 19(4), 477-490. https://oi. org/10.1016/S0743-0167(03)00027-5.

Payne, G. T., Kennedy, K. H., \& Davis, J. L. (2009). Competitive dynamics among service SMEs. Journal of Small Business Management, 47(4), 421-442. https://doi.org/10.1111 j.1540-627X.2009.00277.x.

Pe'er, A., \& Keil, T. (2013). What doesn't kill you makes you stronger: de novo entry in clusters. Journal of Business Venturing, 28(3), 354-372. https://doi.org/10.5465 /ambpp.2008.33725185.

Penrose, E. T. (1959). The theory of the growth of the firm. New York: Wiley.

Pfeffer, R. (2017). Location and strategy-analyzing the effect of the local environment on a portfolio of strategyperformance-relationships of Bavarian Key-Tech SMEs. Hamburg: Dr. Kovac.

Podsakoff, P. M., MacKenzie, S. B., Lee, J. Y., \& Podsakoff, N. P. (2003). Common method biases in behavioral research: a critical review of the literature and recommended remedies. Journal of Applied Psychology, 88(5), 879-903. https://doi. org/10.1037/0021-9010.88.5.879.
Porter, M. E. (1990). The competitive advantage of nations. New York: Free Press.

Pouder, R., \& St. John, C. H. (1996). Hot spots and blind spots: geographical clusters of firms and innovation. Academy of Management Review, 21(4), 1192-1225. https://doi. org/10.5465/amr.1996.9704071867.

Powell, W. W., Koput, K. W., \& Smith-Doerr, L. (1996). Interorganizational collaboration and the locus of innovation: networks of learning in biotechnology. Administrative Science Quarterly, 41(1), 116-145. https://doi.org/10.2307 12393988 .

Radicic, D., Pugh, G. \& Douglas, D. (2018). Promoting cooperation in innovation ecosystems: evidence from european traditional manufacturing SMEs. Small Business Economics, https://doi.org/10.1007/s11187-018-0088-3.

Ripollés, M. \& Blesa, A. (2019). And yet, non-equity cooperative entries do improve international performance: uncovering the role of networks' social capital. Small Business Economics, https://doi.org/10.1007/s11187-019-00186-1.

Rivera, L., Sheffi, Y., \& Knoppen, D. (2016). Logistics clusters: the impact of further agglomeration, training and firm size on collaboration and value added services. International Journal of Production Economics, 179, 285-294. https://doi. org/10.1016/j.ijpe.2016.05.018.

Rodríguez-Serrano, M. Á., \& Martín-Armario, E. (2017). Bornglobal SMEs, performance, and dynamic absorptive capacity: evidence from Spanish firms. Journal of Small Business Management. https://doi.org/10.1111/jsbm.12319.

Rogelberg, S. G., \& Stanton, J. M. (2007). Understanding and dealing with organizational survey nonresponse. Organizational Research Methods, 10(2), 195-209. https://doi.org/10.1177/1094428106294693.

Rothwell, R., \& Dodgson, M. (1991). External linkages and innovation in small and medium-sized enterprises. $R \& D$ Management, 21(2), 125-138. https://doi.org/10.1111 j.1467-9310.1991.tb00742.x.

Rumelt, R. P. (1984). Towards a strategic theory of the firm. In R. B. Lamb (Ed.), Competitive strategic management (pp. 556570). Englewood Cliffs, NJ: Prentice-Hall.

Schilling, M. A., \& Steensma, H. K. (2001). The use of modular organizational forms: an industry level analysis. Academy of Management Journal, 44(6), 1149-1169. https://doi. org/10.5465/3069394.

Schoonhoven, C. B. (1981). Problems with contingency theory: testing assumptions hidden within the language of contingency theory. Administrative Science Quarterly, 26(3), 349377. https://doi.org/10.2307/2392512.

Sharifi, H., \& Zhang, Z. (1999). A methodology for achieving agility in manufacturing organisations: an introduction. International Journal of Production Economics, 62(1-2), 7-22. https://doi.org/10.1016/S0925-5273(98)00217-5.

Shaver, J. M., \& Flyer, F. (2000). Agglomeration, economies, firm heterogeneity, and foreign direct investment in the United States. Strategic Management Journal, 21(12), 1175-1193. https://doi.org/10.1002/1097-0266(200012)21:12<1175 ::AID-SMJ139>3.0.CO;2-Q.

Smallbone, D., North, D., \& Kalantaridis, C. (1999). Adapting to peripherality: a study of small rural manufacturing firms in Northern England. Entrepreneurship and Regional Development, 11(2), 109-127. https://doi.org/10.1080 /089856299283227. 
Stearns, T. M., Carter, N. M., Reynolds, P. D., \& Williams, M. L. (1995). New firm survival: industry, strategy, and location. Journal of Business Venturing, 10(1), 23-42. https://doi. org/10.1016/0883-9026(94)00016-N.

Suarez-Villa, L., \& Walrod, W. (1997). Operational strategy, $\mathrm{R} \& \mathrm{D}$ and intra-metropolitan clustering in a polycentric structure: the advanced electronics Industries of the los Angeles Basin. Urban Studies, 34(9), 1343-1380. https://doi. org/10.1080/0042098975466.

Tallon, P. P., \& Pinsonneault, A. (2011). Competing perspectives on the link between strategic information technology alignment and organizational agility: insights from a mediation model. MIS Quarterly, 35(2), 463-486. https://doi. org/10.2307/23044052.

Tsang, E. W. K. (2000). Transaction cost and resource-based explanations of joint ventures: a comparison and synthesis. Organization Studies, 21(1), 215-242. https://doi. org/10.1177/0170840600211004.

Virkkala, S. (2007). Innovation and networking in peripheral areas - a case study of emergence and change in rural manufacturing. European Planning Studies, 15(4), 511529. https://doi.org/10.1080/09654310601133948.

Westhead, P., Ucbasaran, D., \& Binks, M. (2004). Internationalization strategies selected by established rural and urban SMEs. Journal of Small Business and Enterprise Development, 11(1), 8-22. https://doi.org/10.1108 /14626000410519065.
Wiklund, J., \& Shepherd, D. A. (2009). The effectiveness of alliances and acquisitions: the role of resource combination activities. Entrepreneurship Theory and Practice, 33(1), 193-212. https://doi.org/10.1111/j.1540-6520.2008.00286. $\mathrm{x}$.

Wiklund, J., Patzelt, H., \& Shepherd, D. A. (2009). Building an integrative model of small business growth. Small Business Economics, 32(4), 351-374. https://doi.org/10.1007/s11187007-9084-8.

Williams, R. (2009). Using heterogeneous choice models to compare logit and probit coefficients across groups. Sociological Methods \& Research, 37(4), 531-559. https://doi. org/10.1177/0049124109335735.

Williams, R. (2010). Fitting heterogeneous choice models with oglm. Stata Journal, 10(4), 540-567. https://doi.org/10.1177 /1536867X1101000402.

Yusuf, Y. Y., Musa, A., Dauda, M., El-Berishy, N., Kovvuri, D., \& Abubakar, T. (2014). A study of the diffusion of agility and cluster competitiveness in the oil and gas supply chains. International Journal of Production Economics, 147(Part B), 498-513. https://doi.org/10.1016/j.ijpe.2013.04.010.

Publisher's note Springer Nature remains neutral with regard to jurisdictional claims in published maps and institutional affiliations. 